Narmo M.,Wondimu P.A, Lædre O. (2018). "Best Value Procurement (BVP) in a Mega Infrastructure Project." In: Proc. 26 $6^{\text {th }}$ Annual Conference of the International. Group for Lean Construction (IGLC), González, V.A. (ed.), Chennai, India, pp. 23-33. DOI: doi.org/10.24928/2018/0285. Available at: www.iglc.net.

\title{
BEST VALUE PROCUREMENT (BVP) IN A MEGA INFRASTRUCTURE PROJECT
}

\author{
Mikkel Narmoㅁ, Paulos Abebe Wondimu², Ola Lædre ${ }^{3}$
}

\begin{abstract}
The Norwegian Government recently established a new public company called New Roads with the aim to create more value for money within road investment. To meet government expectations, New Roads has started to use Best Value Procurement (BVP) in mega infrastructure projects. BVP emphasizes contractor selection and risk management from the beginning of the project to add value and reduce waste in all project phases. The purpose of this research is to explore the experience of client and vendor personnel with the implementation of BVP so recommendations can be given for future application. In addition to a literature review, one of the first BVP projects was studied through 11 in-depth semi-structured interviews with key informants. Both client and vendor applauded the approach. Three significant shared positive experiences with the method were found: better risk management, realistic performance expectations, and efficient procurement procedure. BVP is one of several approaches that can be used to award contracts based on qualification rather than price. In addition, the method brings risk management to the beginning of the project.
\end{abstract}

\section{KEYWORDS}

Best Value Procurement (BVP), Public Procurement, Infrastructure projects, Lean, ECI

\section{INTRODUCTION}

Infrastructure projects are growing in scale and complexity. Productivity problems in the construction industry are a global challenge (Pekuri et al. 2014). The Norwegian government sees the need for more effectiveimplementation strategies to increase value creation in infrastructure projects. The government claims that more efficient implementation strategies in infrastructure projects allow projects to be completed faster with lower project costs (Norwegian Ministry of Transport and Communications 2013). Toimplement the strategy, the government established a new public company called New Roads, a streamlined client organization.

1 M.Sc. Student, Department of Civil and Transport Engineering, Norwegian University of Science and Technology (NTNU)/Project Engineer, Veidekke AS, Phone +47 99415674, narmo@live.no

2 PhD Candidate, NTNU, Trondheim, Norway/Senior Engineer, Norwegian Public Roads Administration (NPRA), Norway, +4790111814, paulos.wondimu@ntnu.no/ paulos.wondimu@vegvesen.no

3 Assoc. prof., Dr.Ing., NTNU, Trondheim, Norway, +4791189938, ola.ladre@ @ntnu.no 
In order to build infrastructure projects more efficiently, New Roads involves contractors earlier and uses design-build contracts (DB). As one of the methods to include contractors, the company uses Best Value Procurement (BVP). BVP is a procurement- and management approach that aims to minimize inefficiency and waste of resources by contractinga vendor with a highlevel of expertise(Kashiwagi 2016).BVP is one of severalapproachesthat can be used to implement early contractor involvement (ECI)to increase value in public projects(Wondimu et al. 2016). BVP is one of the ways to award contracts based on qualification rather than only price (Storteboom et al. 2017). Collaborative approaches such as integrated project delivery (IPD), project alliancing, and project partnering have a similar focus (Lahdenperä 2012).

BVP was developed at Arizona State University by Dean Kashiwagi in 1992. The method has been modified and changed several times (Kashiwagi 2016). Best Value Approach and Best Value Performance Information Procurement System (BV PIPS) are names that also are used to describe this method. This paper uses the term BVP for consistency.

There is limited documentation related to BVP in the Norwegian construction industry. This paper explores the experiences of participants in a Norwegian infrastructure project and addresses the following research questions:

- How was Best Value Procurement implemented?

- What were the participants' experiences withusing Best Value Procurement?

- How can Best Value Procurement be improved for future use?

The research is limited to a single case and explores the experiences of the client and the winning vendor with the method. At the time this analysis was carried out, the case project had just started the execution phase. As a result, there search did not explore the approach during the execution phase.

\section{RESEARCH METHOD}

The research was carried out based on literature review and a single case study. The case was studied using eleven in-depth semi-structured interviews and a document study. A case study is suitable for research questions seeking to explain how or why asocial phenomenon works(Yin 2014). Therefore, the case study is an appropriate method to address the research questions. The studied case is presented in Table 1.

Table 1: Case presentation

\begin{tabular}{cccc}
\hline Project Name & Description & Year & Cost (USD) \\
\hline E6 Arnkvern - Moelv & 24km road expansion & $2017-2020$ & $\$ 287,000000$ \\
\hline
\end{tabular}

A total of $11 \mathrm{key}$ persons, 4 from the client and 7 from the winning vendor, were interviewed from the case project. The interviews were conducted through in-depth semistructured interviews based on an interview guide. The interview guide was developed based on the research questions. All interviews were carried out face to face at the interviewee's offices. The interview took on average 60 to 90 minutes. Since it was a semi-structured interview, the informants were able to diverge from the theme and focus 
on what they found interesting. While the interviews followed a prepared guide, they were flexible enough to create an interesting discussion on the subject (Bryman and Bell 2015). During the interviews, field notes were takenand the interviewswere recorded. To achieve quality and credibility in the research, a summary of the interview was sent to the informants for reviewing. After the interviews, documents provided by interviewees were studied to achieve data triangulation (Yin 2014).The data were hand-coded and analyzed hand-in-hand with the data collection, and findings were written up based on the description of Creswell (2013).

\section{THEORETICAL FRAMEWORK}

\section{LEAN WITHIN BVP}

Lean is a way to design a production system to minimize waste and maximize value (Koskela et al. 2002). It is important to include lean elements in the contract in order to assure lean implementation (Toolanen et al. 2005). Advocates of lean construction promote early contractor involvement (ECI) to further reduce waste. ECI can be used in the construction sector to reduce waste by creating organizational integration in the early phase of a project(Wondimu et al. 2016). There are several approaches to implement ECI in the public sector(Wondimu et al. 2016). One of them is BVP. Kashiwagi (2016) describes BVP as a new procurement, risk management and project management approach.

Clients usually resist transparency, especially when it comes to revealing their budget for a project (Ballard 2008). When BVP is used as a procurement approach, the client seeks a transparent contract where as much of the project risk as posible is identified in advance. Transparency is created by providing dominant information during communication (Kashiwagi 2016).BVP has four phases as illustrated in Figure 1.

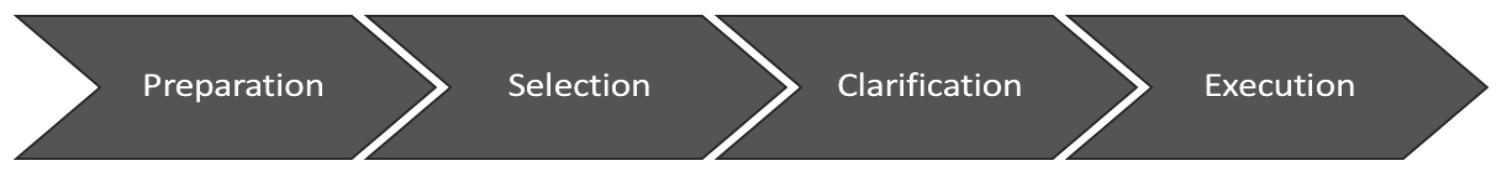

Figure 1: Four phasesof BVP

\section{Preparation Phase}

Rijt et al. (2016) label this phase as the preparation phase where the main goal is to prepare the client organization for implementing the BVP method. Kashiwagi (2016) describes BVP as a difficult shift in paradigm that replaces the client's decision-making, management, direction and control with the utilization of contracted expertise. The client must choose a sponsor in the organization who understands the BVP philosophy completely and choose a core team that will be trained in this new method (Sullivan 2010).

The central concern for the client is "what" is going to be achievedas a result of finishing the project. "How" becomes the vendor's responsibility (Rijt et al. 2016).

The final step in the preparation phase is compiling a core document describing the project objective and scope, weighting the selection criteria, and establishing the project 
budget ceiling. When the budget ceiling is known by the vendors, they can adjust their scope accordingly or decline to participate (Kashiwagi 2016). There is a risk that an incorrect budget ceiling may be set. Therefore, when working with the ceiling budget, vendors should be consulted to determine the budget (Rijt et al. 2016). According to Kashiwagi (2016), pre-qualification is optional in BVP, but it could be beneficial in markets with high vendor capacity. Pre-qualification limits the use of resources for the client and non-qualified vendors (Lædre 2009).

The literature on the preparation phase mainly focuses on preparing the client organization for the new approach.

\section{Selection Phase}

During the selection phase in BVP, the client should seek out the vendor with the highest level of expertise for the lowest cost. The client uses the following five selection criteria to select an expert vendor: Level of Expertise (LE), Risk Assessment (RA), Value Added (VA), price, and interview. The weighting of criteria can vary, but Kashiwagi (2016) and Rijt et al. (2016) state that priceshould be the least important factorcompared to qualifications because of the budget ceiling. In the selection phase, the client uses four filters: project capability (LE, RA and VA), interview, prioritization and dominance check before entering the next phase: clarification (Kashiwagi 2016). These four filters are explained in detail below.

During filter 1, each vendor must differentiate itself based on their company's expertise via the project capability submittals consisting of three 2-page documents. In the LE document, vendors differentiate themselves with non-technical dominant information that describes why they have the capabilities to fulfill the client requirements supported by previous performance data. The RA document is where the vendor identifies significant risks of the project that they do not have control over (client's risk), along with a plan for risk mitigation. The VA document includes proposals or recommendations that can add significant value to the project. The project capability is anonymous and will be rated by the evaluation committee before filter 2 , interviews (Kashiwagi 2016).

Filter 2 is the interview of key personnel. This interviewshould be as short as possible, 20 minutes is sufficient (Kashiwagi 2016). It is comparable to a job interview where selected individuals are interviewed separately. Through dominant information, they should be able to explain their plan for project success (Rijt et al. 2016).

In filter 3 , the client uses the rating criteria to prioritize the vendors. This is the first time the price is revealed to the committee. Based on the committee rating, the highest scoring vendor is addressed as the prioritized Best Value vendor (Rijt et al. 2016).

During filter 4 is a dominance check. Before entering the clarification phase, a dominance check is performed on the best value vendor to ensure that they are the best value for the lowest cost (Kashiwagi 2016). The dominance check investigates the accuracy of the ratings from the selection committee, verifying the information given by the prioritized vendor and determines whether the cost rules (if any) are met.Snippert (2014) states that information verification of the vendor before the clarification phase has great importance. 
The BVP approach has a specific selection phase with five selection criteria. However, the method gives very little room for selection based on technical solutions.

\section{Clarification Phase}

When the prioritized BV vendor entersthe clarification phase, the objective is to clarify their offer. At this point, it is essential that the BV vendor explainwhat is included in their project scope and what is out of scope. By creating transparency in the offer, client expectations are likely to be more realistic. For the first time in the process, the vendor has to show technical competence by revealing his plans. This includes providing a detailed project schedule and milestone schedule, along with a plan for performance measurements through key performance indicators (Kashiwagi 2016).

The vendor presents the risk management plan (RMP) during the clarification phase. The RMP includes a list of identified risks, aplan for mitigating risk and an action plan if a listed risk occurs. The client owns the risk and is financially responsible for it, while the expert has no risk (Kashiwagi 2016). RMP and the weekly risk report (WRR) are included in the vendor's contract. Together they create transparency and remove the need for management and control by the client (Kashiwagi 2016). If the client accepts the vendor's offer, the contractis signed after the clarification phase.

\section{Execution Phase}

After awarding the best value vendor that was selected as the expert during the selection phase and confirmed it in the clarification phase, execution begins. The risk management plan (RMP) becomes a dynamic document during the execution phase through the weekly risk report (WRR). The RMP and the WRR are the primary tools in the execution phase. They allow the client to perform quality assurance on the vendor (Kashiwagi 2011; Rijt et al. 2016). The vendor sends an updated WRR to the client every week to create transparency in the project. If the client's organization has several BVP projects in their portfolio, a collection of all the WRRs form a Director's Report (DR).In the DR, the client can easily get an overview of total project performance (Rijt et al. 2016).

\section{FINDINGS AND DISCUSSION}

Figure 2 shows the structure of the findings and discussion section. It is structured using the three research questions and organized underthe four phases in BVP. 


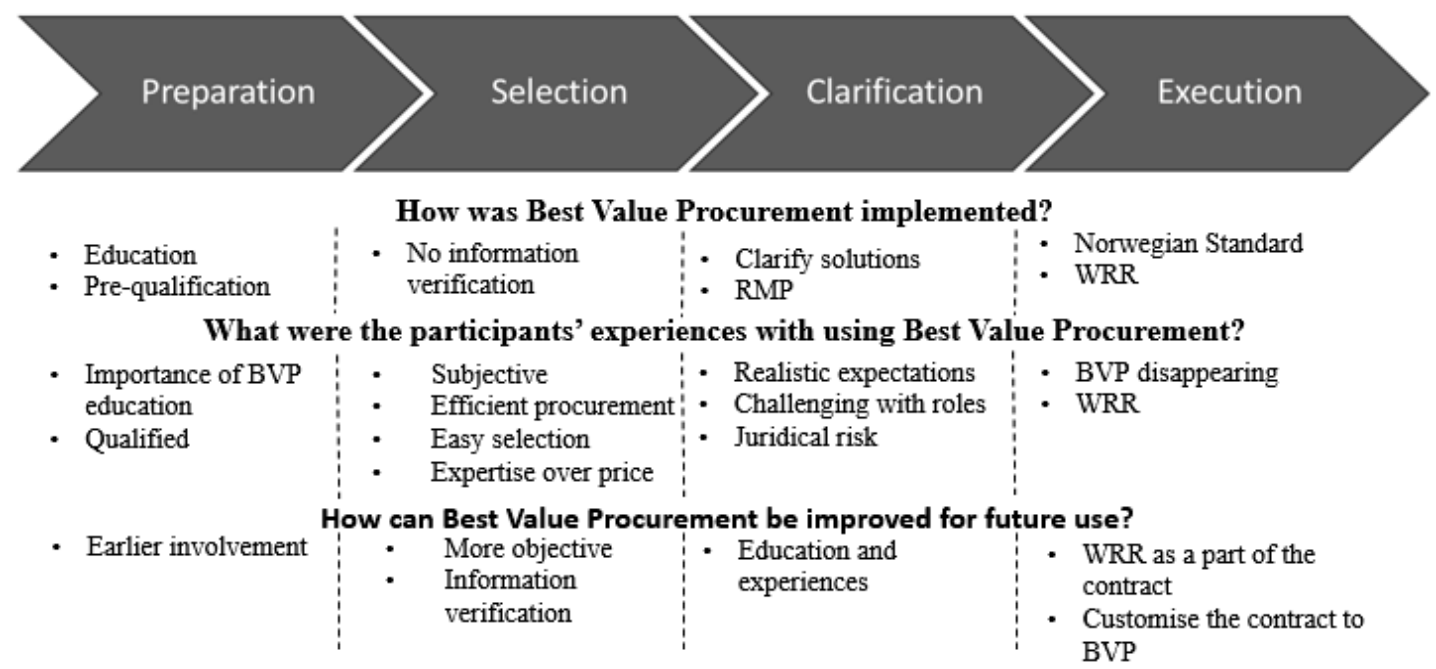

Figure 2: Findings as presented in the findings and discussion section

\section{HOW BVP WAS IMPLEMENTED}

In the preparation phase, the client used the Norwegian translation of the BVP book of Rijt et al. (2016) as a guideline. The client selected a sponsor and a core team according to the recommendations in this book. Not all of the participants in the client's core team were educated externally in the BVP approach. Unlike the client, the winning vendor trainedthe participants in the tender team externally. In addition, both the client and the vendor involved external BVP experts to support them during the preparation phase. By the end of the preparation phase, the client had developed a core document (request for proposal) with five project goals and a budget ceiling. Pre-qualification was also carried out, where by the client selected four vendors to participate in the tender competition.

During the selection phase, each of the four pre-qualified vendors submitted an envelope with two pages describing Level of Expertise (LE), two pages on Risk assessment (RA) and two pages on Value Added (VA). The client interviewed three persons from each vendor. These interviews were recorded and transcribed. The price was submitted in a second envelope to ensure a fair selection. Table 2 shows the client's weighting of the selection criteria.

Table 2: Selection criteria and weighting

\begin{tabular}{lccccc}
\hline Criteria: & Level of expertise & Risk Assessment Plan & Value added & Price & Interview \\
Weighting: & $25 \%$ & $15 \%$ & $10 \%$ & $25 \%$ & $25 \%$ \\
\hline
\end{tabular}

After prioritizing the vendors, the client invited the highest scoring vendor to the clarification phase without dominance check or verification of the tendering information. During the clarification phase, there was a high level of interaction. The vendor presented the Risk Management Plan (RMP), Weekly Risk Report (WRR) and Key Performance Indicators (KPI) before clarifying planned technical solutions for the client. The contract was signed 6 months after the project was announced for tender. The contract was based 
on the Norwegian standard regulations for design and build contracts (NS 8407). Also, the client had a contract option for the maintenance of the road for the next 20 years. To sum up, the implementation of BVP was in line with the recommendations of Rijt et al. (2016).

At the time the data collection was completed, the project had been in the execution phase for only two and a half months. The interviewees' initial experience from the execution was that they had kept the WRR up to date and so far had managed to keep the BVP mindset.

\section{EXPERIENCES WITH BVP}

During the preparation phase, both client and vendor mentioned the importance of educating their teams in BVP since the approach demands a different mentality than traditionalmethods. A respondent from the client suggested that one of the reasons for choosing BVP in complex projects is that it steers the client to obtain a reliable and trustworthy vendor.

In BVP, qualifications are given more weight than price. This is appropriate when the client wants a qualified vendor. The client does not have to be concerned about the technical solutions during the preparation phasesince these will be explained during the clarification phase.

Both client and vendor expressed that they experienced the selection phase as transparent, so they did not worry about legal issues. All four interviewees from the client were part of the evaluation committee in the selection phase, and they all agreed that the prioritized vendor stood out from the competitors during the selection phase. Selection was based on the vendor's past preformance.The interview process was especially useful for the evaluation committee since it revealed which of the vendors best understood what the client needed.

Two of the client interviewees emphasized that the 6pagesin the first tender envelope made the selection phase more efficient. It forced the vendors to present only the most essential information. At the same time, the vendor was positive about being evaluated on expertise rather than lowest price. Still, they had to put a great deal of work into estimating the cost and providing the 6 tender pages.

The vendors' responses for how to meet the project goals described in the tender document were used for evaluation. It appeared that the project goals could be interpreted in several ways. As a result, the vendors' recommendations on how to meet these goals took very different directions, so it was difficult for the client to directly compare the recommendations. Because of this, the evaluation committee had to do subjective evaluations of these responses.

According to most of the respondents, the clarification phase was important for developing a good relationship between the two contracting parties. During this phase, the participants from the vendor and client are allowed to socialize. The client gets to know the vendor's personnel, theirtechnical solutions, and their work ethic before signing the contract. The risk management plan (RMP) was the primary focus throughout this phase, and the weekly risk reporting (WRR) began. As a result, both the client and the vendor found this phase useful. 
Interviewees from both the client and vendor stated that the scope of the tender was clearly specified, and the client's experience was that the vendor led this phase. The parties experienced openness between them. For example, the vendor was transparent regarding quality differences in the road pavement. If they weregoing to maintain the road for the next 20 years, the quality would need to be high. If not, the quality might be low to save cost. This transparency enabled the client to adjust expectations before contract signing.

The challenging part of the clarification phase was to define the new roles for both the client and vendor personnel. In BVP, the vendor is the expert. Thus, the client should not direct, manage and control the vendor. This was challenging primarilyfor the client personnel since most of them come from traditional roles in the construction sector.

If the tender from the vendor doesn't meet the client needs, the vendor could be disqualified. So far, no vendors have been disqualifiedfor any Norwegian BVP projects. Therefore, the uncertainty is high regarding what the outcome of such a short coming would be. It is possible to identify BVP as an efficient procurement procedure for both the client and vendors since it is less resource-demanding than traditional procurement procedures, particularly because only one vendor goes on to the clarification phase and develops the project.

During this research, the case study project had just started the execution phase. It is therefore difficult to report the experiences with BVP in this phase. However, the vendor interviewees indicated that there is a tendency for the BVP philosophy to dissipate, even though they have maintained the WRR and tried to keep the BVP mindset.

This contract is based on the Norwegian standard regulations for design and build contracts (NS 8407), and BVP is not part of the contract.An example that vendor raised was about a client risk that they had been reporting for several weeks in the WRR along with a risk-reducing measure. Before the vendor was able to initiate this risk-reducing measure, the risk occurred. As a result, the risk affected project progress. When the vendor presented a claim for compensation since the risk had been reported in the WRR, the client's lawyer responded that the riskwas not reported in line with the contract (NS 8407). Therefore, the client was not fully responsible for the risk. However, this dispute was quickly resolved when the project manager of the vendor and the project manager of the client decided to meet and discuss the issue. From that point on, the vendor has carefully followed the contract to minimize the risk of a new dispute.

\section{RECOMMENDATIONS FOR FUTURE IMPROVEMENTS}

Regarding the preparation phase, the interviewees from both the client and the vendor agreed that there is potential for value creation if the vendor is involved earlier than was the case here. More specifically, the vendor should be involvedbefore the zoning plan is decided. The zoning plan prevented the vendor from choosing an optimal road alignment and construction method. The contract allows the contractor to try to change the zoning plan, but that would require an uncertain political process in the local municipality. Therefore, the recommendation is to involve the vendor before the zoning plan has been finalized. 
Based on the document study and observations, the selection phase seems to be more subjectively oriented than what is described in the literature. This is unfortunate, as it might lead to incorrect vendor selection. In the two pages describing Level of Expertise, the vendors should explain why they are capable of achieving the project goals in the best possible way. An example of a goal in the case project is "minimize disadvantages for all road traffic groups." This phrasing leads to an interpretation of "disadvantages" by both the evaluation committee and the vendors' tendering teams. When the written part of the selection phase is subjective, and the interviews will be subjective, then the whole selection becomes vulnerable. The authors recommend making this stage more objective by formulating the project goals in a clearlyobjective mannerand by stating in the tendering documents that the vendors can only submit objective claims.

The selection phase isprimarilybased on claims from the vendor. The vendor should support their claims by referring to previous performance. To ensure transparency in the process and to prevent vendors from submitting exaggerated past performance claims, it is crucial that the client verifies the information given by the vendor in the dominance check before entering the clarification phase.

The challenges in the clarification phase are related to the mentality of the vendor and client personnel. None of the interviewees complained about their roles. They accepted that the vendor is an expert and the client is a non-expert, but they said it was difficult to stay in those roles. More education and experience with the method will help the participants to understand and define their role better in the future. Since the method is new in Norway, it is important to transfer the experience between projects.

The primary tool in the execution phase is the WRR. Our findings indicate that the vendor changed their WRR practice for two reasons. First, WRR was not part of the contract. Second, the standard NS 8407 contract was not customized to fit another reporting system. Both the client and the vendor agreed that starting the risk management in the early phase had a positive effect. If the client wants to use the risk management plan from BVP in future projects, then the WRR should be part of the contract. Furthermore, the standard contract should be customized so that it suits the WRR reporting system.

\section{CONCLUSION}

Overall, the client and the vendor in the investigated project had a positive experience with BVP. As a result, they are enthusiastic for future use. However, this experience identified three major advantages of BVP over traditional procurement processes:

- Better risk management

- Realistic expectations of client's and vendor's performance

- Efficient procurement, with less waste.

The risk management approach for the case project was received with satisfaction from both parties. Vendor personnel expressed their expectation that they will use the same risk management with or without BVP in future projects. Realistic expectations in the clarification phase before contract signing create transparency and minimize the risk 
of conflicts. Further more, BVP is an efficient procurement procedure for both the client and vendors since it is less resource demanding than traditional procurement procedures.

Projects that are open for more than one solution benefit from ECI when using the vendor's expertise in the early phase. During ECI implementation, awarding the vendor by qualifications rather than only price is beneficial. BVP is one of several approaches that can be used to award based on qualification rather than price. In addition, the approach brings risk management to the beginning of the project.

In the future, it is recommended that the experiences of the vendors that did not succeed in the selection phase be investigated. Future studies should also consider the effect of this procurement approach in the project execution phase. Furthermore, more case studies on future BVP should be carried put to compare the findings from this study.

\section{REFERENCES}

Ballard, G. (2008). "The Lean Project Delivery System: An Update." Lean Construction Journal, 1-19.

Bryman, A., and Bell, E. (2015). Business research methods, Oxford University Press, USA.

Creswell, J. W. (2013). Research design: Qualitative, quantitative, and mixed methods approaches, Sage publications.

Kashiwagi, D. (2011). "Case study: Best value procurement/performance information procurement system development." Journal for the Advancement of Performance Information \& Value, 3(1).

Kashiwagi, D. (2016). "Best Value Approach." Tempe, AZ: KSM Inc.

Koskela, L., Howell, G., Ballard, G., and Tommelein, I. (2002). "The foundations of lean construction." Design and construction: Building in value, 211-226.

Lahdenperä, P. (2012). "Making sense of the multi-party contractual arrangements of project partnering, project alliancing and integrated project delivery." Construction Management and Economics, 30(1), 57-79.

Lædre, O. (2009). "Kontraktstrategi for bygg-og anleggsprosjekter." Tapir akademiske forlag Trondheim.

Norwegian Ministry of Transport and Communications (2013). "National Transport Plan 2014-2023 ". Report to the Storting (White paper).

Pekuri, L., Pekuri, A., and Haapasalo, H. "Analysing the problem of procurement in construction." Proc., 22nd Annual Conference of the International Group for Lean Construction, IGLC \& Akademika forlag Oslo, 39-50.

Rijt, J. v. d., Santema, S. C. (2016). «Prestatieinkoop: met Best Value naar succesvolle projecten». SCENTER

Snippert, T. (2014). "The best value approach at Rijkswaterstaat: a model of recommendations to improve the implementation of the clarification phase of the best value approach."Master thesis, University of Twente.

Storteboom, A., Wondimu, P., Lohne, J., and Lædre, O. (2017). "Best Value Procurement - The Practical Approach In The Netherlands." Procedia Computer Science, 121, 398-406. 
Sullivan, K. T. (2010). "Quality management programs in the construction industry: Best value compared with other methodologies." Journal of Management in Engineering, 27(4), 210-219.

Toolanen, B., Olofsson, T., and Johansson, J. "Transparency and cooperation: essential factors of lean constructing." Proc., Annual conference of the International Group for Lean Construction: 18/07/2005-21/07/2005, International group for lean construction, 127-133.

Wondimu, P. A., Hailemichael, E., Hosseini, A., Lohne, J., Torp, O., and Lædre, O. (2016). "Success factors for early contractor involvement (ECI) in public infrastructure projects." SEB16 Build Green and Renovate Deep, Elsevier`s Energy Procedia, Tallinn and Helsinki.

Wondimu, P. A., Hosseini, A., Lohne, J., Hailemichael, E., and Lædre, O. (2016). "Early Contractor Involvement in Public Infrastructure Projects." Proc. 24th Ann. Conf. of the Int'l. Group for Lean ConstructionBoston, MA, USA, sect.3 pp. 13-22.

Yin, R. K. (2014). Case study research: Design and methods, Sage publications. 